\title{
Collaborative Strategic Foresight and New Product Development in Chinese Pharmaceutical Firms
}

\author{
Xiaoqing $\mathrm{Li}^{\wedge *}$, David Sarpong*, and Catherine L. Wang* \\ ^ Senior Lecturer in Strategy and Entrepreneurship, Brunel Business School, Brunel \\ University London, Kingston Lane, Uxbridge, Middlesex, UB8 3PH, United Kingdom \\ Email: Xiaoqing.li@brunel.ac.uk (Corresponding author) \\ *Brunel Business School, Brunel University London, Kingston Lane, Uxbridge, Middlesex, \\ UB8 3PH, United Kingdom
}

\begin{abstract}
We integrate insights from open innovation and collaborative strategic foresight (CSF) to theorise collaborative innovation practice. Adopting a case-based approach, we draw qualitative insights from two Chinese pharmaceutical firms - one private and one state-owned, both engaged in new product development (NPD) projects. Focusing on how firms leverage CSF to support their NPD, we offer an interpretive account of how the two firms take different approaches to orchestrating their strategic partnerships to identify, explore and exploit opportunities for innovation. Our study sheds light on how focal firms, through SF practices of perceiving, prospecting, and probing, translate ideas and insights gained from collaborating partners into action to support their innovation processes. Expanding and shifting the focus of traditional strategic foresight from an inward-looking orientation to an outward-looking CSF, we show how focal firms could tap into distributed knowledge embedded in sources located beyond the theoretical boundaries of the firm. We argue that appropriately managed CSF at different stages of NPD could help companies to better sense, seize and integrate potentialities and limits otherwise overlooked by their competitors. We reveal that the type of ownership, an unexplored factor, explains a firm's different CSF approaches (explorative vs exploitative) in innovation for NPD.
\end{abstract}

Keywords: Collaborative strategic foresight, open innovation, new product development, Chinese pharmaceutical firms

(C) 20XX IEEE. Personal use of this material is permitted. Permission from IEEE must be obtained for all other uses, in any current or future media, including reprinting/republishing this material for advertising or promotional purposes, creating new collective works, for resale or redistribution to servers or lists, or reuse of any copyrighted component of this work in other works. 


\section{Introduction}

Strategic foresight (SF), as an organisational capability for exploring and exploiting limits and potentialities otherwise overlooked by competitors, has come to dominate contemporary discourse on successful open innovation for new product development (NPD) (Andersen and Andersen, 2014; Gordon et al., 2020; Lee et al, 2019; Zhu et al., 2019). In practice, many firms have responded to calls for better integration of SF in the open innovation process (Korreck, 2018; Rohrbeck and Gemünden, 2011) by adopting forward-looking practices - to help them manage the fleeting context in which they conceive, create and capture sustainable value from their innovation (Rohrbeck and Kum, 2018; Schwarz et al., 2019). Recognising the high stakes involved, firms now devote considerable effort to developing what has come to be known as collaborative strategic foresight (CSF): SF that goes beyond the theoretical boundaries of the firm, building on partnerships to keep abreast of new innovative practices and emerging technological trajectories (Calof et al., 2018; Heger and Boman, 2015). CSF expands the boundaries of traditional SF to include leveraging distributed knowledge sources through joint discussion and analysis with partners (Gattringer et al., 2017). Yet, as we describe later, fundamental questions remain concerning how focal firms employ CSF to translate ideas and insights from their collaborative partnership into actions to support their innovation processes. The shift from internal-based SF to outward-looking CSF epitomises interaction with partners and even competitors in the value network (Fritzsche, 2018; Weiner et al., 2019) and has two fundamental implications for theorising CSF in organising for NPD.

First, CSF marks a strategic shift from a 'trend-impact-reaction' chain to 'trend-context (interaction)-strategy' (Daheim and Uerz, 2008, p.335) when identifying opportunities for innovation. Interactions with partners as promoted by foresight scholarship help firms remedy the fundamental deficiencies associated with their corporate foresight exercises (Sarpong and Meissner, 2019), overcome barriers in open innovation (Bogers et al, 
2018) and challenge firms to 'think the unthinkable' in ways that expand the range of innovative opportunities (Heger, and Boman, 2015). In this regard, CSF facilitates open innovation, by targeting potential partners whose capabilities and visions complement the firm's own competences and images of the future (Gattringer et al., 2017; Heger, 2014). Thus, CSF practices in organising can enable a faster lead time, contribute to ongoing assessments of the novelty, performance and potential market success of new products, in ways that can help firms learn and react faster to further market needs (Jissink et al., 2014; Yoon et al., 2018).

Second, CSF is interactive in nature and facilitates the exchange of deep tacit knowledge among diverse participants (Weigand, et al., 2013). The collaborative approach, with the expanded foresight horizon, provides a context for high-quality foresight activities (Heger and Boman, 2015). Insights derived from the interaction trigger the focal firm to review its own practices, their underlying assumptions and subsequently to embed the insights into future organisational responses and practices (Calof et al., 2018). In other words, CSF provides opportunities for firms to assimilate internal and external knowledge as well as their integration across organizational boundaries, an ability which is defined as ambidexterity (Paliokaite and Pacesa, 2015). An ambidextrous organisation can exploit current market opportunities and existing capabilities for short-term firm performance, and explore new opportunities to prepare for the future (Mich et al., 2012; Raisch and Zimmermann, 2018); it also has combined skills to manage core and non-core businesses (McGrath et al., 2006). Furthermore, the focal firm can use different approaches at different points in time to manage the paradox of exploration and exploitation (Maclean et al., 2020) while knowing competing priorities in innovation enabled by CSF; hence CSF fosters organisational ambidexterity (Paliokaite and Pacesa, 2015; Rohrbeck and Gemunden 2011). Overall, CSF has the potential 
to significantly boost collaborating firms' innovation output and overall competitiveness (Ehls et al., 2016; Pittaway et al., 2004).

Although recent research has highlighted how CSF has come to be labelled and identified in the context of NPD (see: Weigand et al, 2014; Weiner et al., 2018; Zeng, 2018), empirical work exploring how they cumulatively support NPD processes is sparse. However, the questions remain concerning how focal firms engage CSF to leverage ideas and insights from their collaborative partnership into actions to support their innovation processes. We follow Sarpong et al. (2014) in surmising that these questions are often relegated because of the "theoretical and methodological complexities involved in mapping the tasks, connections and architectures that foresight processes require".

In response to this lacuna, we investigate how firms engage CSF in open innovation for NPD, drawing on qualitative evidence from two Chinese pharmaceutical firms: one private and one state-owned. We observe that innovation in the Chinese pharmaceutical industry, as anywhere else, has long regulatory approval cycles and hence hardly any firms are able to single-handedly pursue NPD ( $\mathrm{Li}$ et al., 2016). This makes an interesting and relevant context for comparing and contrasting how firms can employ CSF to leverage relevant insights from their collaborating partners to support innovation. We make salient contributions to the SF literature: our study posits that the traditional SF boundary should be expanded in the NPD context to create value through collaborative partnership. It contributes to the understanding of the micro-foundations of SF, by identifying strategic practices employed by firms to leverage the 'know-how' of partners to support the NPD processes.

Specifically, we explore how the collaborative 'foresightful' practices through perceiving, prospecting and probing, channel more and deeper future insights into actions at each stage of NPD to facilitate innovation. Our study has practical implications for how 
pharmaceutical companies could appropriately manage CSF by dynamically re-defining the foresight boundaries at different NPD stages to support innovation.

\section{Theoretical Background}

\subsection{From strategic foresight to collaborative strategic foresight in open innovation}

The traditional closed model of innovation that relies on in-house idea generation has been challenged as a result of knowledge becoming very modular and widely distributed (Calof et al., 2018; Fritzsche, 2018). This is especially the case in the pharmaceutical industry, where innovation is evolving towards a more network-based and open process (Dong and McCarthy, 2019; Van der Duin, 2006), in response to technological changes and the ever increasing distribution of knowledge. As 'open innovation' comes into the scene, many firms actively seek information and ideas from actors located beyond their organisational boundaries and frequently integrate external partners in their innovation and value-adding activities (Bogers, et al., 2019; Ven der Duin et al., 2014). Increasingly, firms need to develop their SF potential in order to profit from their open innovation networks (Calof et al., 2018; Nambisan et al., 2018). By SF, we refer to the creative evaluation and (re)configuration of sources of potentialities and limits to future resources and productive outcomes (Chia, 2008; Sarpong and Maclean, 2014). As a distributed organising capability, SF enables organisations to detect discontinuous change early, interpret the consequences for the firm and formulate effective responses, while maintaining a coherent and functional forward-looking view (Rohrbeck and Kum, 2018).

Prior literature theorises SF as a "refined sensitivity for detecting and disclosing" (Chia, 2004, p.22) future relevant information which provides opportunities to prepare for several possible future scenarios of the business environment (Fergnani, 2020). In this regard, a plethora of foresight practices ranging from business war-gaming to counterfactual analysis have been deployed at the organisation level (cf. Popper, 2008; Iden et al., 2017; Schwarz et 
al., 2019). Foresight is not simply to build a tool for the use at a future time, but to bring future insights into the present, and bridge goals and the present state with strategies and actions (Hines et al., 2017; Gordon, Rohrbeck, Schwarz 2019; Paliokaite and Pacesa, 2015). Of particular relevance to our study is the work of Rohrbeck (2010) and Rohrbeck and Kum (2018) which identifies three generic strategic foresight practices of perceiving, prospecting and probing (3Ps), which firms may employ to organise and translate ideas and insights into actions to support their innovation processes. 'Perceiving' refers to the identification and analyses of trends and events in the business environment; 'prospecting', akin to sense-making, involves the translation of inarticulate or unconscious signals into insights; 'probing' encompasses activities aimed at transforming the insight generated through prospecting into actions hitherto unthought-of by competitors.

While this stream of literature has extended our understanding of the context within which strategic foresight is nurtured, the traditional SF approach, focusing on within-firm practices, is restricted to internal structures and existing mental models and may result in one dimensional narrow-sightedness and strategic myopia (Gattringer et al., 2017; Heger and Boman, 2015). In addition, managerial foresight decisions might also be constrained by bounded rationality and managerial cognitive limits (e.g. context, mindset, experience and time limit in a changing environment) (Mackay and McKiernan, 2004; Shala, 2018). To transverse these limitations, many organisations now employ CSF, which prioritises the search for ideas and insights located beyond the conventional organisational boundaries. Organisations collaborating across boundaries can detect 'the right' future developments five years ahead of competition, which would not be possible if they had relied on their own foresight (Wiener, 2018, p60). CSF fosters 'outside-the-box thinking', allowing firms to tap into knowledge embedded in the context beyond their immediate value network or domain of existing operations (Gattringer et al., 2017; Van der Duin et al., 2014). 
Emphasising the shift to CSF as a distributive capacity, the emerging literature recognises the link between CSF and open innovation: both are externally oriented, share techniques and methodologies which, when taken together, can be of enormous value to innovation performance (Calof et al., 2018; Heger and Rohrbeck, 2012). In this regard, CSF strengthens innovation partners' potential to explore emerging technologies, disrupt existing technological trajectories and develop products of the future. Thus, while open innovation drives the processing of often disparate and complicated information collected from both internal and external networks, CSF prioritises the integration of the processed information into meaningful, future-oriented knowledge. Thus, CSF helps validate, refine and prioritise ideas and exploit them towards an idealised future vision (Calof et al., 2018). From this perspective, we argue that it is imperative to integrate CSF in each stage of the NPD process: discovery, development and commercialisation. However, the question is: how do focal firms explore and exploit CSF to leverage relevant insights from their collaborating partners to support innovation at each stage of the NPD process? Below, we draw on the 3Ps (Rohrbeck, 2010; Rohrbeck and Kum, 2018) to delineate how CSF comes to be identified in the context of NPD in pharmaceutical firms.

\subsection{Incorporating the foresight practices of perceiving, prospecting and probing in open} innovation

Inspired by Choo's (1996) 'knowing organisation' principle (organisations use information to construct meaning, create knowledge and make decisions) and Daft and Weick's (1984) model of organisations as interpretative systems, Rohrbeck and Kum (2018) propose a foresight framework - perceiving, prospecting, and probing (3Ps). The 3Ps reflect the similar terrain of the six steps defined by Hines et al (2017) in achieving SF competence (framing, scanning, futuring, visioning, designing, adapting), but goes one step further by extending it with particular attention to the phase of probing (Gordon et al., 2019). The 3Ps are 
interconnected and observable practices (Rohrbeck and Ram, 2019) which enable us to capture and examine how SF supports the stages of NPD in pharmaceutical firms.

\subsubsection{Perceiving idea identification at the discovery stage}

The early stage of NPD in the pharmaceutical industry is characterised by high uncertainty and high failure rates because little information is available and predictions are not very accurate (van der Duin and Hartigh, 2009). Firms' priority at this stage is to explore new product ideas (see Figure 1). SF-perceiving practices are aimed at identifying and linking embodied know-how and capabilities to innovation opportunities (Jolly, 1997). These activities are shaped by market and technological insights, as practised by the focal firm and its partners (Rohrbeck and Kun, 2018). Activities that engage external experts through brainstorming, expert panels or future workshops/conferences can help reduce blind spots in the focal firm's peripheral vision (Hojland and Rohrbeck, 2018; Shoemaker, 2019). The result of the perceiving practices is the sensing and identification of what can be described as weak and strong signals of change, ahead of the competition (Jissink et al., 2014; Rohrbeck and Kum, 2018). This may involve the leveraging of the embodied knowledge of the innovation network, orchestrated by the focal firm to improve its understanding of the 'product concept' which involves the integration of both technologies and the user's performance expectations. Overall, perceiving practices play an initiator role in innovation, triggering new insights, concepts and idea propositions (Rohrbeck and Gemunden, 2011).

\subsubsection{Prospecting potentialities and limits at the development stage}

Prospecting kicks in during the development stage of NPD, translating signals into insights though a process of sense-making, which involves the interpretation of the received signals and their consequences for the yet-to-be-realised innovation (Gavetti and Menon, 2016; Paliokaite and Pacesa, 2015; Rohrbeck and Kum, 2018). Prospecting enables the focal firm to gain deep and reinforced understanding of the yet-to-be-realised innovation. The tipping point 
is the moment when the focal firm can foresee a product that could overcome real or perceived technology and market barriers (Hojland and Rohrbeck, 2018). The gained insight may allow the focal firm to identify alternative pathways and superior courses of action that are likely to allow it to create and capture sustainable value from the yet-to-be-realised innovation (Rohrbeck and Kum, 2018; Sarpong and Maclean, 2012). Thus, prospecting tends to use more structured, future-oriented techniques, such as value chain analysis, case probabilities and impact simulations (Sarpong and Maclean, 2014; Popper, 2008). By gaining more knowledge about the consequences of a choice, the focal firm may be able to identify viable responses to challenges arising from the NPD process. We surmise that both perceiving and prospecting fall into the domain of forward-looking cognitive search and can uncover both local and distant alternatives (Gavetti and Lvinthal, 2000). Alternatives are evaluated based on the actor's incomplete mental model of the world and built on the accumulated tacit knowledge (Hojland and Rohrbeck, 2018).

\subsubsection{Probing at the commercialisation and production stage}

While prospecting practices offer insights into the future of the yet-to-be-realised innovation, probing activities specifically aim to translate the garnered insights into actions (Costanzo, 2004; Hojland and Rohrbeck, 2018). Probing, therefore, 'triggers meaningful organisational responses to change' (Hojland and Rohrbeck, 2018, p. 735) and legitimises the search for alternative courses of action (Rohrbeck and Kum, 2018, p. 107). Probing practices typically move from 'cognitive search' (perceiving and prospecting) to 'experimental search' (Gavetti and Levinthal, 2000). It focuses the 'mind' of the focal firm on finding solutions to perceived and anticipated problems that have the potential to derail the technology-market coupling process (Gavetti and Menon, 2016). Thus, the practice of probing relies exclusively on trial and error experiments (Gavetti and Rivkin, 2007). Examples of activities underpinning probing may include the establishment of living labs, where experiments are brought out of 
the focal firm's R\&D (Research \& Development) departments to real life environments with the participation of users and network partners (Fritzche, 2018; Kim et al., 2019).

To conclude, SF, manifested in a set of practices of perceiving, prospecting and probing, helps organisations benefit from both cognitive (perceiving, prospecting) and experimental (probing) searches (Hojland and Rohrbeck, 2018). However, these practices rarely engage with external actors (e.g. Rohrbeck and Kumd, 2018). The only exceptions are the incidental findings of Hojland and Rohrbeck (2018) showing that partnership can bring significant insights into the prospecting practice in exploring new markets, and those of Costanzo (2004) demonstrating that probing through partnership reveals opportunities that would not have otherwise been identified. SF practices help build organisation's core dynamic capabilities sensing, seizing, and recombination and reconfiguration (Schwarz, Rohrbeck, and Wach, 2018; Teece, 2017). Scanning and interpretative activities refer to 'sensing', acting upon it helps 'seizing' opportunities (Teece, 2007). Studies mix the 3Ps together, and found SF practices mainly contribute to sensing activities and to a lesser extent on nurturing the seizing capability or activity initiation (Heger and Boman, 2015; Gattringer et al., 2017; Rhisiart et al., 2015; Schwar, Rohrbeck, Wach, 2018). While SF is seen as the microfoundation of dynamic capabilities, our understanding of how the $3 \mathrm{P}$ practices are employed and manifested in building dynamic capabilities is incomplete. Particularly, there is a lack of empirical research into how SF should be expanded in the NPD context to leverage insights from collaborating partners through perceiving, prospecting and probing.

\section{--- Insert Figure 1 here ---}

\section{Research Methods}

We develop our contribution in the context of the Chinese pharmaceutical firms because they face intensive competition in NPD subsequent to significant regulatory changes in accordance with China's economic reform. On 1st January 1993, the major amendments to the Patent 
Law came into effect in China, marking a historical transformation for the Chinese pharmaceutical industry (SIPO, 2011). The amendments stipulated that pharmaceutical products, methods and usage can all be patented, endowing inventors with true rights (Hill and Judith, 1993; Okadal And Nagaoka, 2017). This meant that Chinese pharmaceutical firms could no longer copy drug formulas patented by foreign companies after 1993. This motivated Chinese pharmaceutical firms to pursue alternative pathways to business development: to manufacture generic drugs once the foreign firms' patents expire; to purchase the intellectual property rights of a patent drug (with extremely high costs); or to invest in developing innovative drugs (Cao, 2004).

Drug development in China follows a four-phase process similar to that in the Western countries: laboratory test (Phase I), animal test (Phase II), clinical trials (Phase III) and post marketing surveillance (Phase IV) (SFDA, 2005; Dimasi et al., 2003; CDER, 1998; FDA, 1998). The four phases involve a complex and volatile process requiring collaboration with external partners and ushered in a highly developed foresight capability for firms to navigate. The complicated nature of the NPD process, therefore, places concurrent demands on pharma firms to leverage different SF approaches at different stages of NPD, enabling firms to create and capture value from NPD.

\subsection{Case selection}

We employed a qualitative case study research strategy (Yin, 2009) to allow us to focus on our key objective - to investigate how Chinese pharmaceutical firms leverage CSF at each stage of NPD. Specifically, we focused on the NPD processes of two firms - one privately owned and the other state-owned. Both firms are located in Beijing where there is a density of high-tech firms (Yam et al., 2004). A two-case approach selected in the same industry allows more powerful analytical conclusions to emerge from each of the two cases than from a single case study alone (Yin, 2009). 
We adopted Buck's (2011) guidance for case selection by employing a two-stage approach in selecting the case organisations (Buck, 2011; Eisenhardt, 1989). First, we started with an informal sampling selection with broad selection criteria: high-tech enterprises operating in the pharmaceutical industry located in Beijing. We then applied the following criteria to screen firms in the first stage: (a) to focus on firms that are active in NPD, so firms which only produce generic drugs or traditional Chinese medicine are excluded; (b) as a complete NPD process in the pharmaceutical industry takes a long time (PhRMA, 2013), firms included in this study must have been in operation for at least 10 years. Based on the above criteria, we approached firms recommended by personal contacts and by cold calls, resulting initially in four selected firms.

We then applied theoretical sampling and identified two firms (Statepharma and Privatepharma) from the four initial cases, based on theoretical reasons (Eisenhardt, 1989). First, while collaboration with other firms was found in all four initial cases, in order to explore in-depth insights in the leveraging of CSF in innovation, we selected cases with a minimum of two or more collaborative arrangements with external partners aimed at improving the NPD processes. Second, as this study aims to reveal the pattern of CSF activities reflected in each stage of NPD, we chose two firms from the same pharmaceutical industry to hold industry constant. Third, the choice of a state-owned firm (Statepharma) and a private enterprise (Privatepharma) helped compare, contrast and control the impact of governance and ownership structure of a firm on its choices of CSF practices and the kind of activities they engaged in. The different governance structures in state-owned and private enterprises provided contrasting insights into endowed resources and organisational context, elucidating the underpinning logic of the choice of CSF approaches in NPD. Finally, both firms invested in NPD intensively. Statepharma developed more than 10 patented products and Privatepharma had two patented products. Moreover, the two firms selected were willing 
to take part and hence our continued access was granted. Therefore, our two cases - one state-owned and one private, in the same industry and the same city, were purposely chosen to reduce extraneous variation and focus on our research objective (Eisenhardt, 1989; Pettigrew, 1988).

\section{Case 1. Statepharma}

Statepharma was one of the top five pharmaceutical firms in China in terms of investment in NPD. Originating as a military medical centre in 1937, Statepharma became a state-owned pharmaceutical company in 1954 and was publicly listed in 1997. Located in Beijing and neighbouring universities and research institutes, it capitalised on the location to access research resources, outputs and advanced knowledge related to NPD. Statepharma focused on the 'development' of drugs, that is, converting semi-finished new products into marketable products. Its own research centre served product development for all its subsidiary manufacturers, covering three key product lines: large infusion, cardiovascular medicine and hypoglycaemic medicine. The research centre's key responsibility was to provide market-ready drugs for the subsidiaries. The speed of commercialisation of new drugs was vital for its survival.

\section{Case 2. Privatepharma}

Privatepharma was a leading firm in Hepatitis B research in China. Unlike Statepharma, Privatepharma focused on 'research' into new drugs, providing liver disease diagnosis and treatments. Founded in 1994, Privatepharma was a private enterprise located in Beijing. The Founder was an expert in infectious disease, being the first person in China to propose immunotherapy, marking a departure from the universal but less effective treatment for liver disease. The Founder developed a new diagnosis method and personalised treatment, targeting patients on whom conventional treatment was ineffective. Privatepharma's first patent was a new therapy, including two drugs and a vaccine for Hepatitis B. Privatepharma experienced a 
very difficult start-up period and even rented labs to do experiments. After more than ten years' development, Privatepharma built its own research labs and moved from outsourcing research to in-house R\&D.

\subsection{Data collection}

Data for our empirical inquiry were collected chiefly through semi-structured interviews with NPD managers and team members in 2008 and 2009. Data were then kept up to date with the recent NPD development of the two firms until the end of 2015 based on secondary data (e.g. the company websites, annual reports and other trade publications). To collect in-depth data, we used purposive sampling (Lincoln and Guba, 1985) to identify key informants who were most knowledgeable about NPD (Saunders et al., 2009). Informants selected covered the key roles in the R\&D Department (Privatepharma) and the Research Centre (Statepharma): the heart of NPD within the two case study firms. In Privatepharma, the R\&D Manager had worked there since its inception. In Statepharma, the Manager of Administration responsible for co-ordinating all the NPD activities internally and externally at the Research Centre had worked for the firm for about 16 years and the Manager of Information Management, responsible for evaluating NPD projects, had worked at Statepharma for 14 years. We also selected other key persons who had knowledge about the NPD and management, such as the General Manager, the Founder and the Manager of Production.

In total, we conducted eight interviews (five with Privatepharma, and three with Statepharma) over a one-year period. All interviews were conducted by the authors face-to-face on the respective sites of the firms. Once we had conducted five interviews with Privatepharma and three interviews with Statepharma, additional insights from further interviews were marginal, indicating a point of diminishing returns (Strauss and Corbin, 1998). This indicated that the number of interviews conducted in each firm was sufficient to reveal the NPD process. Therefore, interviews were stopped at this point when incremental 
learning was minimal and no further considerable insights were gained; theoretical saturation was reached (Eisenhardt, 1989).

The interviews were semi-structured and interview questions covered four broad dimensions: a. strategic objectives of NPD and the necessity of involving external partners; $b$. the use of CSF: the collaborative partner, their inputs, the CSF methods, the CSF practices and activities in the daily operation, how they are different at each stages of NPD; c. the value of CSF: the course of action taken, the value of CSF in NPD and the consequences; and d). the rationales behind decisions about selecting the forms of collaboration at different NPD stages. Each interview lasted from one to one and a half hours. All the interviews were recorded and transcribed for data coding and analysis. Where available, we supplemented our interview data with secondary data, such as information on company websites. The data collected from different informants and alternative sources were triangulated (Flick, 2018), before we began the analysis to identify viable theoretical explanations.

\subsection{Data analysis}

Following Eisenhardt's (1989) recommendation for analysing case study data, we adopted three key steps in order to understand how firms leverage CSF in the NPD process. First, we conducted within-case analysis, by drawing a timeline of four key stages of NPD and then zoomed into each stage to identify CSF practices and activities employed to conduct NPD. Second, we conducted cross-case analysis to compare not only similarities, but also differences between the two cases, in order to capture the interaction between the firms and their collaborative partners in NPD, the nature CSF and to understand the dynamics involved in firms' choice of forms of collaboration. Third, we incorporated the themes emerging from the cross-case analysis into a theory of CSF in managing NPD. In particular, we identified three CSF approaches managing different stages of NPD: loosely defined friendship/network, contract-based and lead-operator, as summarised in Tables 1, 2 and 3. 


\section{--- Insert Tables 1, 2 and 3 here ---}

\section{Research Findings}

Our findings suggest that both private and state-owned Chinese 'pharma' (pharmaceutical) firms engaged foresight in collaborations with other organisations at each stage of the NPD process (an open rather than closed innovation). While both firms extended the boundary of foresight to involve collaborative partners through perceiving, prospecting and probing to support innovation, the state-owned firm, although endowed with slack resources, was much more prone to an exploitative, or what we refer to as a ' $\mathrm{D}$ (development)-focused' approach. This was because its government-assigned CEOs were on fixed-term contracts and hence fixated on short-term outcomes. In contrast, the private firm, despite being resource-constrained, was proactive in tapping into distributed expertise beyond the firm's boundaries, reflecting an explorative or 'R (research)-focused' NPD strategy.

\subsection{Perceiving in Stages I and II}

Both the private and state-owned pharmas proactively monitored changes in the external environment for new product ideas in Stages I and II. They predominantly did this through the exploration and exploitation of knowledge and information embedded in the established personal networks of the managers, founders and research employees. Thus, CSF practices at this stage were conducted through informal and ad-hoc collaborative partnership with external experts through workshops and conferences, group discussions and so on. While Privatepharma focused on monitoring the fast evolution of the new technologies for liver diseases, Statepharma prioritised the gathering of information on semi-finished innovation outcomes with the most market potential to refine and upgrade their key product lines. The key founder of Privatepharma, a renowned doctor specialising in Hepatitis B in China, quit his job in a state-owned hospital, where he led national key research projects and received special contribution awards. He always kept himself at the forefront technology through 
networking among the wider expert community. Such informal ways of interacting with doctors and scientists at research institutes and hospitals provided Privatepharma with the flexibility to explore the future changes earlier than competitors. The founder understood that there was a great number of Hepatitis B patients in China and that the method developed in the Western countries (using antiviral drugs to cure HBV) was not effective for all patients. The initial idea of developing technologies and treatment to improve Hepatitis B patients' immune systems was derived from his continuous communication with doctors and scientists about the development in the field (external exploration) together with his experience and his accumulated expert knowledge (internal exploration). Indeed, the external knowledge exploration exposed the innovation team at Privatepharma to increased possibilities of accessing world-leading technologies, that had the potential to open up new opportunities.

'During the coffee break (at the international conference in the US), a leading professor, James Sheffield (pseudonym), who developed the world's first medicine - 'white cellhormone 2' for improving cancer patients' immune system-approached me. He is very interested in my presentation and asked me, 'my new drug might work better than yours on HBV, why don't you do research into it?' I said, 'I did not know, if I knew, I would do it'. He encouraged me to do the test and generously gave me 10 bottles to bring back to China (worth \$50,000 in 1983).'

While Privatepharma proactively engaged in diverse perceiving activities with national and international experts to keep abreast of cutting-edge technology in the field (exploring for long-term R-capability development), Statepharma exploited its collaborative partners' knowledge and expertise for information on chemical compounds with the most commercial potential (for short-term profit maximisation, to enhance D-capability).

'One of our colleagues heard from his friend, who is a research expert, that an anti-hypertensive formula - Number zero- being developed (close to finish of Phases I and II) by an expert in an institute in Shandong, had a high market potential if successful. But that expert did not have resources to carry on clinical trials (Phase III). We then approached this expert quickly and purchased this semi-finished product (Manager of Information Dept., Statepharma).' 
Here, foresight exercises conducted with external experts through informal partnership kept both firms constantly informed of diverse, reliable and critical NPD information at not only the research forefront, but also the market forefront.

'They are practising doctors, they know new product gaps, supply and demand gaps of certain products. The insights gained from the continuous interaction with them prompted us to define our innovation around three key areas in China: large infusion, cardiovascular medicine and hypoglycaemic agents. (Manager of Information Dept., Statepharma).'

'Involving these friendship-based relations in our foresight activities for NPD is critical because they are the origin of innovation, the collaboration with these experts both at home and abroad kept our research cutting-edge, not in a closed way (Founder, Privatepharma).'

Although the external experts were loosely defined and no contracts were found to specify their responsibilities and roles, they formed as an 'ad-hoc advisory board' to provide insights for future innovation and the manager of Privatepharma named them 'an extended $R \& D$ function of the firm'.

\subsection{Prospecting and probing in Stage III}

Once a signal of a likely future new product idea was perceived, both firms investigated the viability of the innovation opportunity by exploring more structured CSF practices with experts in hospitals and research institutes. The focus of innovation at this stage was to transform the new product idea developed in the pre-clinical phase (Stages I and II) into a usable drug through clinical trials. The boundary of foresight practices was refined. The unstructured informal knowledge exchange through loosely defined personal networks was replaced with a more structured governance form with clearly defined processes and rules in a long-term, agreement-based collaboration. Privatepharma prospected alternative treatment 
methods for Hepatitis B, inspired by the exploration of several joint experiments with external experts: one was an antiviral drug (the first generation of antiviral drugs for liver disease, at Guangdong Research Center, China); the other two focused on drugs for improving patients' immune systems: Thymosin (collaborated with several leading experts: a biochemist from the Chinese Academy of Medical Sciences, a biologist from Peking University, and another biochemist from Nanjing University) and 'White Cell Hormone 2' (conducted at Qinhuangdao Immunology Research Centre, China with samples provided by James Sheffield, from the US).

CSF activities in joint research reinforced both firms' understanding of the alternatives. Insights were gained not only from the interaction of partners with different perspectives, but also through the trial-and-error processes. The collaborative insight indicated that screening out the right patients was critical, as the same drug was not effective for all Hepatitis B patients. This reinforced understanding by prospecting different alternatives and triggered a new round of probing for Privatepharma, to develop a diagnostic kit followed by different types of treatment with the three optional drugs. One of the diagnostic technologies included in the kit was screening, which could help analyse patients' genetic types and find out which group of patients was suitable to receive either immune system treatment or antiviral drugs. This diagnostic kit could be used in a variety of industries, e.g. hotels, restaurants, massage parlours, karaoke bars where business must follow strict health checks for infectious diseases. This market potential of the diagnostic technology provided Privatepharma a viable business opportunity.

The intensive interaction with complementary knowledge, new resources, new perspectives and new ways to solve problems not only challenged the mindset of researchers from both Privatepharma and Statepharma but also stimulated them to review their own 
practices through learning by doing. Hence, prospecting and probing practices co-existed at this stage of innovation.

'During the clinical trials (drawing on a cancer treatment in the West using thymus hormone extracted from cows to test and treat Hepatitis B patients), in order to solve the problem of the shortage of cows in China when preparing for the future long-term supply of the new drug, foresight meetings with doctors suggested several alternatives but helped us select pigs to replace cows in order to extract thymus hormone. It worked effectively, particularly for HBV patients with serious infections. This insight, contributed by experienced cancer experts, speeded up our NPD proces, and we became the first to use thymus hormone extracted from pigs to improve the immune systems of Hepatitis $B$ patients in China (Founder of Privatepharma).'

Statepharma's understanding of the anti-hypertensive drug Number Zero was reinforced by the real-time insight gained in experiments.

'While we collaborated with hospitals doctors on the experiments with the anti-hypertensive drug Number Zero, we tested several times and the required effectiveness was still not achieved. Based on their experience and expertise, the doctors suggested that a change of dose would work. Together we worked on adjustment of the dose and eventually made one pill per day sufficient to keep the blood pressure stable' (Manager of the Administrative Dept., Statepharma).

\subsection{Probing in Stage IV}

The focus of the innovation shifted from developing new products to commercialisation and protection. The new drug gained further approval through experiments with larger populations and prepared for mass production. Both firms probed further through partnerships not only with experts and doctors in the field, but other organisations embedded in their value networks, such as manufactures and sub-contractors. Foresight boundaries were refined again, 
and foresight generation was achieved through collaborating with carefully selected partners while both long-term and one-off contract-based collaboration also took place. Probing for the further improvement of the new drug through experimentation helped both firms to maintain open access to critical on-site data, through which the firms gained insights via interactive learning.

'Our best-selling anti-hypertensive drug Number Zero underwent the 2nd round of innovation, as its side effects needed further investigation. External experts in chemistry and pharmacy and hospital doctors were all involved in analysing the causes of the side effects and in finding alternative solutions. The insights from the expert panel showed that refining and purifying one of the chemicals could reduce the side effects. The experiment challenged our original methodology and we had to adjust our operational procedure. We then conducted the fourth phase of clinical trials by collaborating with hospitals again and observed the differences.' (Manager of Information Department, Privatepharma).

CSF probing practices allowed both firms to make timely adjustments and fed discoveries at operational level directly back into the two pharmas' on-going R\&D. It also ensured the use of state-of-art technology and reinforced the understanding of the market. For example, the collaborative foresight partners formed an intelligent network to encourage divergent thinking. While looking at Number Zero's future market together with external experts and sub-contractors, Statepharma interpreted that there should be a great demand for affordable anti-hypertensive drugs in rural areas in China. This insight informed Statepharma to create a tailored product profitably by lowering production costs on Number Zero, as well as informing future new anti-hypertensive drugs.

Privatepharma probed through joint experiments with doctors in hospitals on the diagnostic kit. Probing practices through intensive interaction with doctors on trial-and-error 
experiments formed a rich learning process. Privatepharma brought the problems and solutions back and forth many times and reflected on the insights in operations in order to get the concept proven in experiments. The collaborative probing catalysed the innovation process and the diagnostic kit went through official approval and became Privatepharma's first patented product. Comparatively, insights gained through exploiting international knowledge sources through partnership informed Statepharma to license in semi-finished projects from other countries, such as Germany, even at the stage of Phase IV, in order to commercialise them quickly in China.

At the same time, Privatepharma used collaborative insights to exploit in-house research capability to source in profitable non-core new products (e.g. cosmetics) in order to generate extra income for reinvestment in the core research (triple trajectory: in-house production, outsourcing, and source-in non-core research). The exploitation of developed in-house research capabilities and the exploration of collaborative resources in innovation across different industries helped Privatepharma frame possible future scenarios in the bio-technology field.

With a more stable drug and on-site data, both firms prototyped the production to go through official approval, in order to get a certificate that granted the new drug market access. The interactions with external experts helped both firms to validate their decisions about what should be kept in-house, and what should be outsourced at this stage.

'We think that we need to recruit expert people and invest in new equipment in manufacturing this part of the product, but insights gained from our collaboration signaled that this investment might not be used in the future after the completion of manufacturing this product, we then adjusted our decision. We sought to co-operate with others who are experienced in doing that with higher efficiency and lower costs than us, rather than investing in too much now, being locked in missing future opportunities' 
(Manager of Information Department, Statepharma).

Both firms probed future innovation at this stage through a planned dual trajectory approach (in-house and outsourcing), which allowed them to focus on their core competencies and, at the same time, recombining and reconfiguring to fully exploit internal and external resources and expertise.

'Following the insights from collaborating with external experts, we sometimes break the production of a new drug down into small pieces until making it impossible for others to interpret our new innovation, we will ask others to do the most difficult and costly part, and then we collect and integrate them to continue the rest of research (Manager of Information Dept., Statepharma).

The probing practices at this stage were systematic and intelligent. Collectively probing the future innovation at this stage informed firms to develop a dual or triple trajectory strategy to internalise through ownership in order to protect tacit technological knowledge, commercialise the innovation outcome quickly and generate more patents and drugs, hence being prepared for future competition. CSF enabled both firms to channel more future insights into the front-end of their NPD process.

\section{Discussion}

We explored how firms leverage CSF to support open innovation for NPD. Empirically, we examined how a private and a state-owned Chinese pharmaceutical firm orchestrated their respective NPD partnerships and leveraged others' capabilities and differential images of the future to inform innovation activities. We conceptualised CSF as a set of collective practices involving external partners to support innovation through identifying new product ideas (perceiving), interpreting the consequences of alternatives (prospecting) and actions which allow experimenting the value propositions, drug formulations and commercialisation 
This article has been accepted for publication in a future issue of this journal, but has not been fully edited. Content may change prior to final publication. Citation information: DOI10.1109/TEM.2020.3040041, IEEE Transactions on Engineering Management

potential (probing). By doing so, our study contributes to the strategic foresight and innovation management in several ways.

First, our findings reveal that CSF broadens foresight horizon to benefit from distributed knowledge sources embedded in inter-firm interactions. Our study responds to the call for filling the gap between practice and theory in SF research (see, Iden et al., 2017). It looks at practical approaches to SF and revealed how CSF creates value in innovation - a missing link in the existing literature. While our findings revealed that incorporating external collaborative partners' inputs in terms of complementary or differing knowledge, information, resources, perspectives and ways of doing things into the foresight process not only remedies SF's deficiencies, namely its one-dimensionality (Gattringer et al., 2017; Marion et al., 2015), but also enhances the effectiveness of SF with richer and broader data than that within organisational boundaries in managing innovation process. CSF enabled firms to prioritise opportunities in the context of various uncertainties and resource constraints and also to respond and act earlier than others (Calof et al., 2018; Jissink et al., 2014). Insights gained through on-going interaction with external knowledge sources drove firms constantly to renew and re-configure their routines, practices, knowledge bases and structures, in order to prepare for future competition. CSF enabled both firms to achieve unforeseen novel combinations of knowledge, which could in turn lead to radical and incremental discoveries (Ehls, et al., 2016; Pittaway et al., 2004). On the one hand, this supports the participative communication point of view of the foresight process (Daheim and Uerz, 2008). On the other hand, we go a step further and emphasise that it is the integration of internal and external sources where interaction takes place that helps with communication, creates unique learning-by-doing opportunities, shares tacit knowledge and generates foresight value.

Second, the two firms underwent interactions with the 3Ps (perceiving, prospecting and probing) of CSF over the whole innovation process: comparatively, perceiving practices are 
found appropriate to inform the early stage of NPD (Phase I\&II) for sensing distant new product ideas; probing at the later stage (Phase IV) for capturing and optimising local alternatives; a combination of prospecting and probing at the middle stage of innovation (Phase III) for assessing and legitimating alternatives. Here, thoughts trials (prospecting) are tested (probing), and the iterative experimenting with new solutions in real environments helps the focal firm seize opportunities or new technologies earlier than rivals and prepare for threats before they are materialised. Both firms employ an integrated approach to the 3Ps and iterate between thinking (perceiving, prospecting) and acting (probing) along the NPD process. Integrating happens in every stage, and is particularly peaked in Phase IV, where both firms positioned as a lead-operator to organise multiple CSF relationships with partners. Notably, learning is intensified in probing practices (experimenting at operational level) through actual experience in real environments (learning by doing and real-time foresight), as opposed to learning through a mere representation of the environment in perceiving and prospecting.

Overall, a continuous approach rather than a linear sequence supports the view that it is the pre-adapted firms which can spot the opportunity earlier than others; namely, their capability of sense-making is a higher-order form of experimental learning (Gavetti and Levinthal, 2000; Gavetti and Menon, 2016). This implies that successful NPD needs to incorporate both forward-looking cognitive intelligence and backward-looking experimental wisdom (retrospective sense-making), as well as the co-existence of prospecting and probing in Phase III. Therefore, cognitive searching (through perceiving and prospecting) complements experimental searching (through probing) to avoid missing opportunities and being constrained by a narrow search in a given moment. Mental models, reshaped from intensive interaction with new stimuli derived from perceiving and prospecting practices, help overcome inertia and bounded rationality, reveal blind spots and enlarge choices of 
opportunities (Heger and Boman, 2015; Rohrbeck and Gemunden, 2011). Although the private firm strove to explore new opportunities for radical changes and the state-owned firm aimed to exploit existing resources for incremental innovation (re-innovating existing products, e.g. Number Zero), both firms employed exploratory and exploitative skills simultaneously in innovation. This is because sensing new opportunities is built on a firm's deep understanding of current trends in the industry. Findings show that continuously involving CSF practices (3Ps) in innovation processes helps develop a firm's sensing (perceiving weak and strong signals), seizing (iterative prospecting and probing by identifying tipping point and strategising) and integrating (probing, learning by doing; reconfiguring) aspects of dynamic capabilities. Therefore, CSF can be the antecedent of continuous innovation and change and can facilitate the development of organisational ambidexterity (Rhisiart et al., 2015).

Third, our findings contribute to the open innovation management literature by showing that Chinese pharmaceutical firms appropriately managed CSF activities by dynamically redefining the foresight boundaries at different stages of NPD to support innovation. They started from unstructured CSF practices with loosely-defined personal networks at Phases I and II, through intentional (planned and deliberate) contract-based relationships at Phase III, moving to intelligent and systematic (purposefully CSF practices), lead-operator (dual or triple trajectory) collaboration at Phase IV. First, these CSF methods and practices guaranteed that the sources of knowledge synthesised into the foresight process was reliable, creative and interactive. Second, it helps develop distinctive foresight capabilities (sensing, seizing, integrating) at different stages of NPD respectively. More importantly, to a certain extent it offers insights into effective responses to challenges of managing intellectual property protection during collaborative innovation (Calof et al., 2018), particularly in China, where the institutional environment is not well established. The 
different governance forms of CSF revealed in this study (loose friendship in Phase I \& II, contract-based in Phase III and lead operator involving multiple collaboration with sub-contractors in Phase IV) largely fill the gap in the literature on how CSF helps overcome barriers of open innovation in terms of governance issues at different stages of NPD. This supports the claim that the utility of CSF for innovation depends on the strategic management of individual firms (Pittaway et al., 2004) and that the choice of CSF form also considers the nature of each stage of NPD.

Finally, our findings reveal that the ownership structure of a firm could influence its choices of CSF practices and the kind of activities it engages in when it comes to manage its fleeting futures. The different ownership also means differences in endowed resources, organisational context and governing structure, providing contrasting insights which enrich our understanding of the role of collaborative foresight in innovation. While the national institutional environment in China enabled Statepharma to access financial resources for NPD, it constrained Privatepharma which struggled to raise funds for research. Privatepharma was more likely to take a long-term and explorative foresight perspective than Statepharma. In Privatepharma, engaging CSF was close to a learning process within a broad vision (Research-focused), whereas Statepharma paid more attention to results out of CSF practices (Development-focused). CSF informed NPD in both firms, but Privatepharma was more patient and desired to explore opportunities through learning-by-doing, learning through trial-and-error, and also tolerated failure. Seeing investing in basic research as risky, Statepharma put efforts into the exploitation of CSF to inform which semi-finished new products could be sourced in for profit maximisation. Our study hence contributes to the existing literature that the types of ownership, an unexplored factor (e.g. Hojland and Rohrbeck, 2018), affects firm's CSF practices in open innovation for NPD. Future research on 
SF should bring this factor to the fore, rather than leaving it hidden, or overridden by other factors.

Therefore, CSF manifested at each stage of NPD was underpinned by various organisational theories, such as bounded rationality (cognitive vs experimental search), dynamic capability (sensing, seizing, integrating), organisational ambidexterity (managing radical and incremental innovation simultaneously). This study hence interconnects organisational theories with innovation management. A CSF - 3Ps - open innovation model as detailed in Figure 2 builds a foundation for future research.

\section{-Insert Figure 2 here}

\section{Conclusion}

This study reveals how Chinese pharmaceutical firms leverage collaborative strategic foresight practices to support open innovation in stages of NPD. Engaging CSF practices in NPD contributes to the development of a firm's sensing, seizing, and integrating foresight capabilities, which are important organisational capabilities enabling some firms to out-perform others. The nature of CSF in open innovation for NPD revealed in this study and the dynamism with which firms refine their foresight boundaries at different stage of NPD contribute to knowledge on foresight in innovation. While the management of intellectual property is the major challenge in open innovation, especially in developing countries where institutional environment is underdeveloped, different governance forms of CSF at different stages of NPD revealed in this study have both theoretical and practical implications. The interactive and dynamic perspective of strategic foresight overwrites the traditional foresight principles, and induces effective strategies in managing innovation. This study therefore enhances our understanding of the link between strategic foresight and management of innovation, an under-researched area in the existing literature. 
Despite our contribution, our study has limitations. Our findings are supported by data from two cases. While the purposely selected two cases offer useful and relevant evidence on how CSF enables open innovation for NPD in pharmaceutical firms, further research is encouraged, to incorporate more cases in order to test our findings in the same or different organisational and industrial settings. The long period of drug development means that it is challenging to trace the whole NPD process of a new drug. Our findings are drawn from interview data from the most appropriate informants who were most knowledgeable about the NPD process in the respective firms; the two cases have been in operation over ten years with rich experience in drug developments. Further research would benefit from longitudinal data collection to track real-time collaborative strategic foresights.

\section{References}

Adegbile, A., Sarpong, D. and Meissner, D. 2017. Strategic foresight for innovation management: A review and research agenda, International Journal of Innovation and Technology Management, 14: 1-33.

Andersen, A. D. \& Andersen, P. D. 2014. Innovation system foresight. Technological Forecasting \& Social Change, 88: 276-286.

Bogers, M., Chesbrough, H., \& Moedas, C. 2018. Open innovation: research, practices, and policies. California Management Review, 60: 5-16.

Buck, T. 2011. Case selection informed by theory, in R. Piekkari, \& C. Welch, (eds.). Rethinking The Case Study In International Business And Management Research, Cheltenham: Edward Elgar. pp. 192-209.

Calof, J., Meissner, D. \& Razheva, A. 2018. Overcoming open innovation challenges: a contribution from foresight and foresight networks. Technology Analysis and Strategic Management, 30: 718-733.

Cao, Y. 2004. Analyzing the impact of China's entry into WTO on the pharmaceutical industry, a report on The Chinese Security, 19 April 2004.

CDER, 1998. The CEDR Handbook, Department of Health and Human Services, Food and Drug Administration, Centre for Drug Evaluation and Research, the US.

Chia, R. 2004. Re-educating attention: What is foresight and how is it cultivated? In H. Tsoukas \& J. Shepherd (Ed.), Managing the future: Foresight in the knowledge economy (21-37). Oxford, U.K: Blackwell. 
Chia, R. 2008. Enhancing entrepreneurial learning through peripheral vision. In Harrison, R.T. and Leitch, C.M. Entrepreneurial learning: Conceptual frameworks and Applications, London: Routledge, pp.27-43.

Choo, C. W. 1996. The knowing organization: How organizations use information to construct meaning, create knowledge and make decisions. International journal of information management, 16 (5): 329-340.

Costanzo, L. A. 2004. Strategic foresight in a high-speed environment, Futures, 36: 219-235.

Daft, R. L., \& Weick, K. E. 1984. Toward a model of organizations as interpretation systems, Academy of management review, 9 (2): 284-295.

Daheim, C. \& Uerz G.2008. Corporate foresight in Europe: from trend based logics to open foresight. Technology Analysis \& Strategic Management, 20: 321-336.

Dimasi, J. A., Hansen, R. W. \& Grabowski, H. G. 2003. The Price of Innovation: New Estimates of Drug Development Costs. Journal of Health Economics, 22: 151-85.

Dong, J. Q., \& McCarthy, K. J. 2019. When more isn't merrier: pharmaceutical alliance networks and breakthrough innovation. Drug Discovery Today, 24: 673-677.

Ehls, D., Korreck, S., Jahn, R., Zeng, M., Heuschneider, S., Herstatt, C., Koller, H.,\& Spaeth, S. 2016. Open foresight: Exploiting information from external sources. Available at SSRN 2764208 (Accessed 15th April 2019).

Eisenhardt, K.M. 1989. Building theories from case study research. Academy of Management Review, 14: 532-550.

FDA, Food and Drug Administration, the US, 1998. The CDER Handbook, Department of Health and Human Services, FDA, Center for Drug Evaluation and Research, revised on Mar. 16, 1998.

Fergnani, A. 2020. Corporate foresight: A new frontier for strategy and management. Academy of Management Perspectives, [In press] doi.org/10.5465/amp.2018.0178.

Flick, U. 2018. Doing triangulation and mixed methods (Vol. 8), London: Sage Publications.

Fritzsche, A. 2018. Corporate foresight in open laboratories - a translational approach. Technology Analysis \& Strategic Management, 30: 646-657.

Gattringer, R., Wiener, M. \& Strehl, F. 2017. The challenge of partner selection in collaborative foresight projects. Technological Forecasting \& Social Change, 120: 298-310.

Gavett, G. \& Menon, A. 2016. Evolution cum agency: toward a model of strategic foresight, Strategy Science, 1: 207-233.

Gavetti, G. \& Levinthal, D. 2000. Looking forward and looking backward: cognitive and experiential search, Administrative Science Quarterly, 45: 113-137.

Gavetti, G. \& Rivkin, W. 2007. On the origin of strategy: action and cognition over time. Organization Science, 18:420-439. 
Gordon, A., Rohrbeck, R., \& Schwarz, J. O. 2019. Escaping the" faster horses" trap: bridging strategic foresight and design-based innovation. Technology Innovation Management Review, 9 (8): 30-42.

Harper, J.C. 2013. Impact of technology foresight: compendium of evidence on the effectiveness of innovation policy intervention, Manchester Institute of Innovation Research, Manchester Business School, University of Manchester, UK.

Heger, T. 2014. A Theoretical Model for Networked Foresight, the XXV ISPIM Conference Innovation for Sustainable Economy \& Society, Dublin, Ireland, 8-11 June 2014.

Heger, T.\& Boman, M. 2015. Networked foresight-The case of EIT ICT Labs. Technological Forecasting \& Social Change, 101: 147-164.

Heger, T. \& Rohrbeck, R. 2012. Strategic foresight for collaborative exploration of new business fields. Technological Forecasting \& Social Change, 79: 819-831.

Hideg, E. 2007. Theory and practice in the field of foresight. Foresight, 9:36-46.

Hill, D. \& Judith, E. 1993. Chinese patent law: Recent changes align China more closely. The George Washington. Journal of International Law Economics, 27: 359-393.

Hines, A., Gary, J., Daheim, C., \& van der Laan, L. 2017. Building foresight capacity: toward a foresight competency model. World Futures Review, 9 (3): 123-141.

Hojland, J. \& Rohrbeck, R. 2018. The role of corporate foresight in exploring new markets evidence from 3 case studies in the BOP markets, Technology Analysis \& Strategic Management, 30: 734-746.

Iden, J., Methlie, L.B., \& Christensen, G.E. 2017. The nature of strategic foresight resear ch: a systematic literature review. Technological Forecasting and Social Change, 116: 87-97.

Jissink, T., Huizingh, E.K.R.E., \& Rohrbeck, R. 2014. Corporate Foresight: Antecedents and Contributions to Innovation Performance. The XXV ISPIM Conference - Innovation for Sustainable Economy \& Society, Dublin, Ireland, 8-11 June 2014.

Jolly, V. 1997. Commercializing New Technology: Getting from Mind to Market. Boston: Harvard Business School Press.

Kim, J., Kim, Y. L., Jang, H., Cho, M., Lee, M., Kim, J., \& Lee, H. 2019. Living labs for health: an integrative literature review. European Journal of Public Health. doi.org/10.1093/eurpub/ckz105 [In-press].

Könnölä, T., Brummer, V., \& Salo, A. 2007. Diversity in foresight: Insights from the fostering of innovation ideas. Technological Forecasting \& Social Change, 74: $608-626$.

Korreck, S. 2018. Opening up Corporate Foresight: What Can We Learn from Open and User Innovation? Journal of Innovation Management, 6: 153-177. 
Lee, Y., Fong, E., Barney, J. B., \& Hawk, A. 2019. Why Do Experts Solve Complex Problems Using Open Innovation? Evidence from the US Pharmaceutical Industry. California Management Review, 0008125619883617 [In press].

Li, X., Zheng, Y. \& Wang, C. L. 2016. Inter-firm collaboration in new product development in Chinese pharmaceutical companies. Asia Pacific Journal of Management, 33: 165 193.

Lincoln, Y. \& Guba, E. 1985. Naturalistic Inquiry. Beverly Hills, CA: Sage.

Mackay, R. B., \& McKiernan, P. 2004. The role of hindsight in foresight: Refining strategic reasoning. Futures, 36: 161-179.

Marion, T. J., Eddleston, K. A., Friar, J. H., \& Deeds, D. 2015. The evolution of interorganizational relationships in emerging ventures: An ethnographic study within the new product development process. Journal of Business Venturing, 30: 167-184.

McGrath, R. G., Keil, T., \& Tukiainen, T. 2006. Extracting value from corporate venturing. MIT Sloan Management Review, 48 (1): 50-57.

Michl, T., Gold, B., \& Picot, A. 2012. The spin-along approach: ambidextrous corporate venturing management. International Journal of Entrepreneurship and Small Business, 15 (1): 39-56.

Nambisan, S., Siegel, D., \& Kenney, M. 2018. On open innovation, platforms, and entrepreneurship. Strategic Entrepreneurship Journal, 12: 354-368.

Okada1, Y. \& Nagaoka, S. 2017. 'Global spread of pharmaceutical patent protection: micro evidence from the international equivalents of drug patents in Japan. Millennial Asia, 8: $26-47$.

Paliokaite, A. \& Pacesa, N. 2015. The relationship between organisational foresight and organisational ambidexterity, Technological Forecasting \& Social Change, 101: $165-181$.

Pettigrew, A. 1988. Longitudinal field research on change theory and practice. Paper presented at the national science foundation conference on longitudinal research methods in organizations. Austin.

PhRMA 2013. Pharmaceutical Research and Manufactures of America. 2103 Profile-pharmaceutical research industry. Washington, DC: PhRMA.

Pittaway, L., Robertson, M., Munir, K., Denyer, D., \& Neely, A. 2004. Networking and innovation: a systematic review of the evidence. International Journal of Management Reviews, 5/6: 137-168.

Popper, R. 2008. Foresight methodology. The handbook of technology foresight, 44-88.

Rhisiart, L., Miller, R., \& Brooks, S.2015. Learning to use the future: developing foresight capabilities through scenario processes, Technological Forecasting \& Social Change 101: 124-133. 
Rohrbeck, R. 2010. Corporate foresight: towards a maturity model for the future orientation of a firm. Heidelberg: Physica-Verlag, Springer.

Rohrbeck, R., Döhler, M., \& Arnold, H. 2009. Creating growth with externalization of R\&D results: the spin-along approach, Global Business \& Organizational Excellence, 28: 44-51.

Rohrbeck, R. 2011. Corporate foresight: towards a maturity model for the future orientation of a firm. Berlin: Physica-Verlag.

Rohrbeck, R. \& Gemünden, H.G. 2011. Corporate foresight: its three roles in enhancing the innovation capacity of a firm. Technological Forecasting \& Social Change, 78: 231-243.

Rohrbeck, R. \& Kum, M. E. 2018. Corporate foresight and its impact on firm performance: A longitudinal analysis. Technological Forecasting \& Social Change, 129: 105-116.

Rohrbeck, R., \& Ram, C. 2019. 'White paper - making Organisations Fit to Drive Desirable Futures', DEHEC Business School, Nice, France. Available at SSRN 3484538.

Sacio-Szymańska, A. \& Nosarzewski, K. 2019. Anticipating and Managing Change in Large Organization Strategic Environment: Using Foresight and Organizational Policy to Enable Futures Literate Decision-Making. In Futures Thinking and Organizational Policy (pp. 133-155). Palgrave Macmillan, Cham.

Sarpong, D., \& Maclean, M. 2012. Mobilising differential visions for new product innovation. Technovation, 32: 694-702.

Sarpong, D. and Maclean, M. 2014. Unpacking strategic foresight: a practice approach. Scandinavian Journal of Management, 30:16-26.

Sarpong, D. \& Maclean, M. 2016. Cultivating strategic foresight in practise: A relational perspective. Journal of Business Research, 69: 2812-2820.

Sarpong, D. and Meissner, D. 2019. Corporate Foresight and Innovation Management, London: Routledge.

Saunders, M.N.K., Lewis, P. \& Thornhill, A. 2009. Research Methods for Business Students (5th Edition), Harlow: FT Prentice Hall.

Schoemaker, P. J. 2019. Attention and foresight in organizations. Futures \& Foresight Science, 1(1), e5. doi.org/10.1002/ffo2.5 [in press].

Schwarz, J. O., Ram, C., \& Rohrbeck, R. 2019. Combining scenario planning and business wargaming to better anticipate future competitive dynamics. Futures, 105: 133-142.

SFDA, State Food \& Drug Administration, P.R.C., 2005. Special review and approval procedure for drug registration of the State Food and Drug Administration, on-line normative documents, decree No. 21, China.

Shala, E. 2018. Foresight and social epistemology: an inquiry into the epistemic versatility of futures research and the potential of a socioepistemic approach, unpublished $\mathrm{PhD}$ thesis, The Karlsruhe Institute of Technology, Karlsruhe, Baden-Württemberg, Germany. 
SIPO, 2011. Patent Law of the People's Republic of China, State Intellectual Property Office of the P.R.C., Beijing, China.

Strauss, A. \& Corbin, J. 1998. Basics of qualitative research: Ground theory procedures and techniques, Newbury Park, CA: Sage.

Van der Duin, P.A. 2006. Qualitative futures research for innovation. Delft: Eburon Academic.

Van der Duin, P.A., Heger, T., \& Schlesinger, M. D. 2014. Toward networked foresight? Exploring the use of futures research in innovation networks, Futures, 59: 62-78.

Van der Duin, P.A. \& den Hartigh, E. 2009. Keeping the balance: exploring the link of futures research with innovation and strategy processes, Technology Analysis \& Strategic Management, 21:333-351.

Vecchiato, R. 2015. Creating Value Through Foresight: First Mover Advantages and Strategic Agility, Technological Forecasting and Social Change, 101: 25-36.

Weigand, K., Flanagan, T., Dye, K. \& Jones, P., 2014. Collaborative foresight: Complementing long-horizon strategic planning. Technological Forecasting and Social Change, 85: 134-152.

Wiener, M., Gattringer, R., \& Strehl, F. 2018. Collaborative open foresight-a new approach for inspiring discontinuous and sustainability-oriented innovations. Technological Forecasting and Social Change. doi.org/10.1016/j.techfore.2018.07.008 [In press]

Wiener, M., Gattringer, R., \& Strehl, F. 2018. Participation in inter-organisational collaborative open foresight A matter of culture. Technology Analysis \& Strategic Management, 30(6): 684-700.

Yin, R.K. 2009. Case Study Research: Design and Methods, 4th Edition. Thousand Oaks, California: Sage Publications, Inc.

Yoon, J., Kim, Y., Vonortas, N. S., \& Han, S. W. 2018. Corporate foresight and innovation: the effects of integrative capabilities and organisational learning. Technology Analysis \& Strategic Management, 30: 633-645.

Zeng, M.A., 2018. Foresight by online communities-The case of renewable energies. Technological Forecasting and Social Change, 129: 27-42.

Zhu, X., Xiao, Z., Dong, M. C., \& Gu, J. (2019). The fit between firms' open innovation and business model for new product development speed: A contingent perspective. Technovation. 86-87: 75-85. 
Figure1. Collaborative strategic foresight approach to organising open innovation

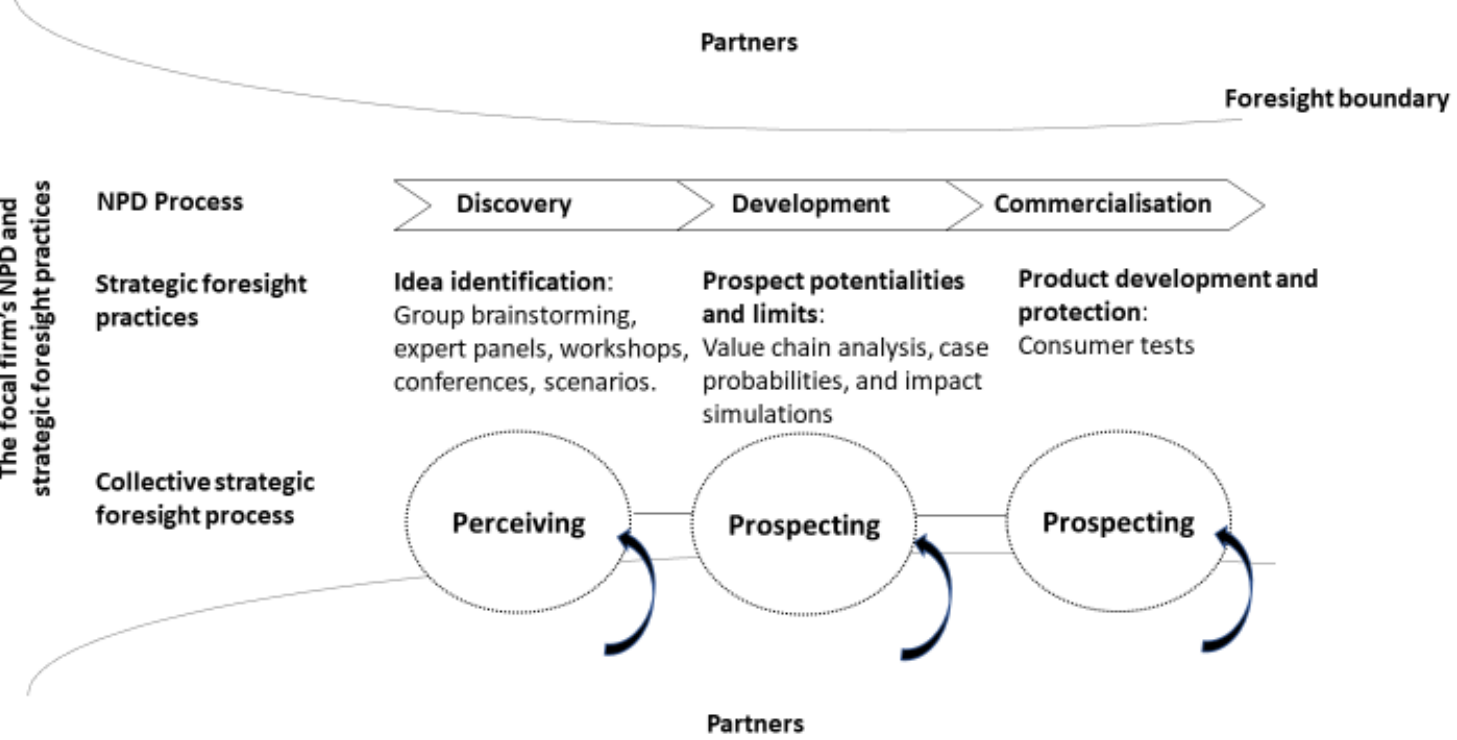

Figure 2. A conceptual framework of collaborative strategic foresight in NPD

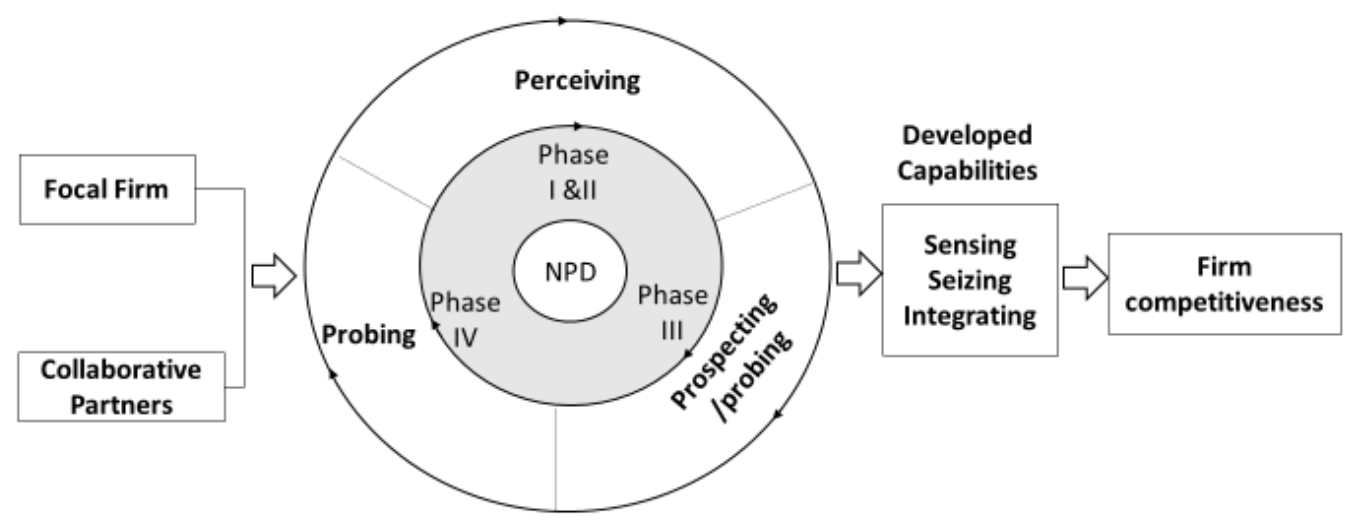


Table 1. Collaborative strategic foresight practices in the NPD: Phases I and II

\begin{tabular}{|c|c|c|}
\hline \multirow[b]{3}{*}{ Objective of NPD } & Privatepharma (R-focused NPD) & Statepharma (D-focused NPD) \\
\hline & \multicolumn{2}{|c|}{ Identification of opportunities for new ideas and potentialities to reducing NPD uncertainties } \\
\hline & Leading research in HBV liver disease in China & $\begin{array}{l}\text { High speed commercialization of research outputs } \\
\text { in } 3 \text { key areas in China: large infusion, } \\
\text { cardiovascular medicine, and hypoglycaemic } \\
\text { medicine }\end{array}$ \\
\hline CSF process & \multicolumn{2}{|c|}{ Perceiving for new product idea identification } \\
\hline CSF methods & \multicolumn{2}{|c|}{ Futures workshops and conferences } \\
\hline Collaborative partners & \multicolumn{2}{|c|}{ Doctors and scientists based in universities, research institutes, and hospitals } \\
\hline $\begin{array}{l}\text { Inputs of partners in } \\
\text { CSF (examples) }\end{array}$ & $\begin{array}{l}\text { - Different 'ways of doing' things, e.g. methods on } \\
\text { improving cancer patients' immune system (which } \\
\text { might be effective in treating liver disease). } \\
\text { - Latest developments on new or similar drugs and } \\
\text { technologies induced in the West e.g. thymic } \\
\text { hormone extracted from cows, white cell hormone } \\
2 \text { on cancer. }\end{array}$ & $\begin{array}{l}\text { - Latest medical research development in the three } \\
\text { key product lines } \\
\text { - Information and suggestions for synthesis of } \\
\text { possible chemical compounds with commercial } \\
\text { potential }\end{array}$ \\
\hline $\begin{array}{l}\text { CSF contributes to } \\
\text { innovation }\end{array}$ & \multicolumn{2}{|c|}{$\begin{array}{l}\text { - Detect signals of change in NPD ahead of competition while interacting with a lot of information } \\
\text { richness across organizational boundaries } \\
\text { - Reduce blind spots and open up to a wider range of innovative opportunities } \\
\text { - Challenge the embedded assumptions, cognitive foundations and limitations and avoid bias about the } \\
\text { future } \\
\text { - Potential to be the first to access to reliable and critical NP information on the research and market front; } \\
\text { enabling to sense opportunities earlier, which is often critical to gain access to scare resources and secure } \\
\text { competitive positions quicker than rivals, e.g. receive new drug samples for cancer in Privatepharma } \\
\text { - Get direct validation of potential next generation of medicines hence to reduce uncertainties }\end{array}$} \\
\hline $\begin{array}{l}\text { Characteristics of } \\
\text { CSF }\end{array}$ & $\begin{array}{l}\text { Be flexible and patient; willing to invest; focused } \\
\text { (e.g. on liver disease) }\end{array}$ & $\begin{array}{l}\text { Planned and impatient; unwilling to invest; diverse } \\
\text { (e.g. any semi-finished drug development with } \\
\text { commercial potential) }\end{array}$ \\
\hline CSF approaches & Explorative & Exploitative \\
\hline Governance of CSF & \multicolumn{2}{|c|}{ Informal, personal network-based } \\
\hline $\begin{array}{l}\text { Foresight capability } \\
\text { developed }\end{array}$ & \multicolumn{2}{|l|}{ Sensing } \\
\hline
\end{tabular}


Table 2. Collaborative strategic foresight practice in the NPD: Phase III

\begin{tabular}{|c|c|c|}
\hline & Privatepharma (R-focused NPD) & Statepharma (D-focused NPD) \\
\hline \multirow[b]{2}{*}{ Objective of NPD } & \multicolumn{2}{|c|}{ Increase the likelihood of success in NP and protect the NPD } \\
\hline & Tangible NPD on HBV liver disease in China & $\begin{array}{l}\text { Reduce uncertainties and speed up the NPD } \\
\text { process }\end{array}$ \\
\hline CSF process & \multicolumn{2}{|c|}{ Prospecting and probing } \\
\hline CSF methods & \multicolumn{2}{|c|}{ Collective exploration and exploitation, collaborative problem solving } \\
\hline Collaborative partners & \multicolumn{2}{|c|}{ Doctors at hospitals } \\
\hline \multirow{2}{*}{$\begin{array}{l}\text { Inputs of partners in } \\
\text { CSF (examples) }\end{array}$} & \multicolumn{2}{|c|}{$\begin{array}{l}\text { - Different perspectives, suggestions, and solutions to solving problems at the operational level } \\
\text { - Access to different resources, e.g. doctors with expertise knowledge, patients as trial participants, } \\
\text { physical facilities. }\end{array}$} \\
\hline & $\begin{array}{l}\text { Mobilization of information on opportunities for } \\
\text { outsourcing in-house research }\end{array}$ & $\begin{array}{l}\text { In search for information on latest medical } \\
\text { development }\end{array}$ \\
\hline $\begin{array}{l}\text { CSF contributes to } \\
\text { innovation }\end{array}$ & \multicolumn{2}{|c|}{$\begin{array}{l}\text { - Intensified interaction with new stimuli reshapes mental models and fosters out-of-box thinking } \\
\text { - Bridge thinking (prospecting) and action (probing) by integrating iterative thoughts trial (prospecting) } \\
\text { and testing (probing) across organisational knowledge boundary, and matching opportunities with } \\
\text { capabilities } \\
\text { - Intensified interaction allows tacit knowledge sharing and creates unique learning opportunities } \\
\text { - Accelerated tacit knowledge accumulation from diverse partners inspires cognitive leaps hence helps } \\
\text { break path-dependency in innovation }\end{array}$} \\
\hline \multirow[t]{2}{*}{ Characteristics of CSF } & \multicolumn{2}{|c|}{ A learning cycle between thinking (cognitive) and testing (experimental) } \\
\hline & Pay attention to the process of CSF & Pay attention to the results out of CSF practices \\
\hline CSF approaches & Exploitative & Explorative \\
\hline Governance of CSF & \multicolumn{2}{|l|}{ Formal, contract-based } \\
\hline $\begin{array}{l}\text { Foresight capability } \\
\text { developed }\end{array}$ & \multicolumn{2}{|c|}{ Seizing } \\
\hline
\end{tabular}


Table 3. Collaborative strategic foresight practices in the NPD: Phase IV

\begin{tabular}{|c|c|c|}
\hline & Privatepharma (R-focused NPD) & Statepharma (D-focused NPD) \\
\hline Objective of NPD & \multicolumn{2}{|c|}{ Commercializing research output and protection of NP } \\
\hline CSF process & \multicolumn{2}{|c|}{ Probing } \\
\hline CSF methods & \multicolumn{2}{|c|}{ Competitive intelligence, benchmarking } \\
\hline Collaborative partners & \multicolumn{2}{|c|}{ Hospital doctors and experts specializing in different areas; manufacturers in value network } \\
\hline \multirow{2}{*}{$\begin{array}{l}\text { Inputs of partners in CSF } \\
\text { (examples) }\end{array}$} & \multicolumn{2}{|c|}{$\begin{array}{l}\text { Analysis on competitors moves vis a vis the firm's NPD; interpret new technological trajectories } \\
\text { and trends, to define potential future market demands for next round of NPD }\end{array}$} \\
\hline & $\begin{array}{l}\text { Mobilizing information on opportunities to } \\
\text { sourcing in non-core research }\end{array}$ & $\begin{array}{l}\text { Building up information on latest cutting-edge } \\
\text { medicine development }\end{array}$ \\
\hline $\begin{array}{l}\text { CSF contributes to } \\
\text { innovation }\end{array}$ & \multicolumn{2}{|c|}{$\begin{array}{l}\text { - Intensified trial-and-error experiments spanning across industry boundaries enhance interactive } \\
\text { learning and help assess and refine the future insights } \\
\text { - Validating, refining, and real world testing alternative solutions entails self-reviewing and } \\
\text { reconfiguring and embedding the insights into meaningful organisational responses } \\
\text { - Accelerate execution of innovation ideas (probing) through multiple exploitation pathways }\end{array}$} \\
\hline Characteristics of CSF & $\begin{array}{l}\text { Long-term view; innovation capabilities - } \\
\text { driven }\end{array}$ & Short-term perspective; financial profit - driven \\
\hline CSF approaches & Exploitative & Exploitative \\
\hline \multirow[b]{2}{*}{ Governance of CSF } & \multicolumn{2}{|c|}{ Lead operator; multiple collaboration with sub-contractors } \\
\hline & $\begin{array}{l}\text { Triple trajectory: in-house production, } \\
\text { outsourcing, and source-in non-core research }\end{array}$ & $\begin{array}{l}\text { Dual trajectory: in-house production and } \\
\text { outsourcing }\end{array}$ \\
\hline $\begin{array}{l}\text { Foresight capability } \\
\text { developed }\end{array}$ & \multicolumn{2}{|c|}{ Integrating } \\
\hline
\end{tabular}

